\title{
Estrogen receptor alpha and androgen receptor are commonly expressed in well-differentiated liposarcoma
}

Davis R Ingram', Lloye M Dillon² , Dina Chelouche Lev ${ }^{1}$, Alexander Lazar ${ }^{3}$, Elizabeth G Demicco ${ }^{5}$, Burton L Eisenberg ${ }^{4}$ and Todd W Miller ${ }^{2^{*}}$

\begin{abstract}
Background: Liposarcoma (LS) is the second-most common type of soft-tissue sarcoma. Despite advances in knowledge and treatment of this disease, there remains a need for more effective LS therapy. Steroid hormone receptors regulate metabolism in adipocytes. Estrogen receptor alpha (ER), progesterone receptor (PR), and androgen receptor (AR) have been implicated in the pathophysiology of other cancer types. We sought to comprehensively determine temporal expression patterns of these receptors in LS.
\end{abstract}

Methods: We analyzed 561 histologically subtyped LS specimens from 354 patients for expression of ER, PR, and AR by immunohistochemistry (IHC) using diagnostic-grade reagents and protocols. The fractions of positively stained tumor cells were scored within each specimen. IHC scores were compared across LS subtypes using the Kruskal-Wallis test, and subtypes were compared using Dunn's post-hoc test. Ages of patients with receptor-positive vs. -negative LS were compared by t-test. Genders and races were compared for hormone receptor positivity using Fisher's exact test and Chi-square analysis, respectively. Recurrence-free survival was compared between receptor-positive and negative patients by log-rank test. $\mathrm{p}<0.05$ was considered significant.

Results: ER and AR were frequently expressed in LS, while few tumors expressed PR. Most of the ER + and $A R+$ samples were of the well-differentiated LS subtype. A smaller fraction of de-differentiated LS expressed ER or AR, but expression was common within well-differentiated regions of tumors histologically classified as de-differentiated LS. In LS specimens from patients who underwent multiple surgeries over time, receptor expression frequently changed over time, which may be attributable in part to intratumor heterogeneity, varying degrees of de-differentiation, and biopsy bias. ER and AR were frequently co-expressed. Receptor status was not significantly associated with gender or race, but AR and PR expression were associated with earlier age at diagnosis. Receptor expression was not associated with altered recurrence-free survival.

Conclusions: ER and AR are commonly expressed in LS, particularly in well-differentiated tumors. These data warrant further functional study to determine receptor function in $L S$, and the potential efficacy of anti-hormone therapies for the treatment of patients with LS.

\footnotetext{
* Correspondence: todd.w.miller@dartmouth.edu

${ }^{2}$ Departments of Pharmacology \& Toxicology, Norris Cotton Cancer Center, Geisel School of Medicine at Dartmouth, Dartmouth-Hitchcock Medical Center, One Medical Center Drive, HB-7936, Lebanon, NH 03756, USA Full list of author information is available at the end of the article
} 


\section{Background}

Approximately 11,280 patients are diagnosed with one of many types of soft tissue sarcoma each year in the U.S. [1]. Liposarcomas (LS) constitute approximately $24 \%$ of extremity and $45 \%$ of retroperitoneal soft tissue sarcomas [2], ranking as the second-most common type of soft-tissue sarcoma. LS occurs in three major biologic subgroups: 1) well- or de-differentiated LS (WDLS, DDLS, most common subgroup), 2) myxoid LS (MLS), and 3) pleomorphic LS (PLS). WDLS and MLS are typically lowgrade tumors, DDLS are often intermediate grade with intermediate risk for metastasis, and PLS are high-grade and clinically aggressive. It is thought that DDLS starts as WDLS, and tumor cells progressively accumulate genetic lesions as they transition to a less differentiated, nonlipogenic state. Progression to DDLS is associated with more aggressive local disease, increased metastatic potential (10-20\%), and increased mortality (50-75\%) [3-6]. LS is typically treated by surgical resection, and high-grade lesions are sometimes treated with adjuvant radiation therapy. DNA-damaging chemotherapy is usually not effective against LS. In addition, tumor recurrence is common, particularly with retroperitoneal LS. Therefore, there exists a need for improved LS therapy.

LS likely originates from a lipogenic precursor cell(s). Since lipogenic metabolism is heavily influenced by steroid hormones [7], and adipocytes express nuclear hormone receptors and steroidogenic enzymes such as aromatase $[8,9]$, we postulated that LS cells may similarly express such receptors. Prior studies in limited numbers of patients reported expression of steroid hormone receptors in a fraction of LS cases [10-17]. To expand upon and clarify these findings, we analyzed 561 LS specimens acquired from 353 patients in the largest LS cohort reported todate to determine the frequencies of expression of estrogen receptor alpha (ER), progesterone receptor (PR), and androgen receptor (AR). Frequent expression of these hormone receptors may prompt clinical testing of antihormone strategies, such as those used to treat patients with cancers of the breast (anti-estrogens) or prostate (anti-androgens), or to control pregnancy (anti-progestins), in order to assess the contribution of these receptors to LS growth. These drugs may ultimately prove useful for the treatment of patients with LS.

\section{Methods}

\section{Patients and tissues}

LS specimens were obtained at Dartmouth-Hitchcock Medical Center and M.D. Anderson Cancer Center between 1986 and 2012 under protocols approved by the Institutional Review Boards of Dartmouth-Hitchcock Medical Center and M.D. Anderson Cancer Center, respectively. Patients provided written informed consent. Tissues were formalin-fixed and paraffin-embedded.
Core samples were used to construct tissue microarrays (TMAs). Clinical records indicated that these TMAs included 379 tumors from 353 patients, where tumors were classified as DDLS ( $n=122)$, WDLS $(n=146)$, MLS $(n=79)$, or PLS $(n=32)$. WDLS and DDLS are thought to represent different stages of disease progression that can co-exist in the same tumor. Hence, some cores taken from DDLS cases were histologically classified as "WDLS." In total, we analyzed 561 core samples, which were classified as 294 WDLS, 123 DDLS, 112 MLS, and 32 PLS based on histological criteria.

Table 1 Baseline characteristics

\begin{tabular}{|c|c|}
\hline Characteristic & $n$ patients \\
\hline \multicolumn{2}{|l|}{ Age at registration } \\
\hline$<30$ years & 9 \\
\hline $30-50$ years & 106 \\
\hline $50.1-70$ years & 180 \\
\hline$>70$ years & 51 \\
\hline Unreported & 7 \\
\hline \multicolumn{2}{|l|}{ Gender } \\
\hline Male & 215 \\
\hline Female & 138 \\
\hline \multicolumn{2}{|l|}{ Race } \\
\hline White & 264 \\
\hline Black & 12 \\
\hline Hispanic & 38 \\
\hline Asian & 7 \\
\hline Unreported & 32 \\
\hline \multicolumn{2}{|l|}{ Primary tumor type } \\
\hline Well-differentiated & 136 \\
\hline De-differentiated & 107 \\
\hline Myxoid & 78 \\
\hline Pleomorphic & 32 \\
\hline \multicolumn{2}{|l|}{ Primary tumor size } \\
\hline$<5 \mathrm{~cm}$ & 15 \\
\hline $5-9.9 \mathrm{~cm}$ & 55 \\
\hline$\geq 10 \mathrm{~cm}$ & 221 \\
\hline Undetermined & 62 \\
\hline \multicolumn{2}{|l|}{ Chemotherapy } \\
\hline Yes & 98 \\
\hline No & 236 \\
\hline Unreported & 19 \\
\hline \multicolumn{2}{|l|}{ Radiation therapy } \\
\hline Yes & 93 \\
\hline No & 239 \\
\hline Unreported & 21 \\
\hline
\end{tabular}




\section{Immunohistochemistry}

Commercially available antibodies against ER alpha (6 F11 monoclonal, dil. 1:35; Leica Biosystems), PR (PgR 1294 monoclonal, dil. 1:200; Dako; recognizes both $\mathrm{A}$ and $\mathrm{B}$ isoforms), and AR (AR441 monoclonal, dil. 1:30; Dako; recognizes both $A$ and $B$ isoforms) were used for immunohistochemistry (IHC). These antibodies are routinely used for in vitro diagnostics in clinical laboratories. A Leica BOND-MAX automated stainer was used with a polymer/HRP detection system. After deparaffinization, 5- $\mu \mathrm{m}$ TMA sections were treated with citrate buffer at $100^{\circ} \mathrm{C}$ for $25-30$ minutes. Slides were probed with primary antibody for 15 minutes, washed, and probed with HRP-polymer anti-mouse IgG for 8 minutes. Signal was detected using 3,3-diaminobenzidine, followed by hematoxylin counterstaining. ER+/PR + breast tumor tissue was used as a positive control for ER and PR IHC. AR + prostate cancer tissue was used as a positive control for AR IHC. Spleen biopsies were included in the TMAs and used as negative control tissues. Tissues were scored based on the estimated percent of positively stained cancer cell nuclei.

\section{Statistics}

IHC scores were compared across LS subtypes using the Kruskal-Wallis non-parametric test, and subtypes were compared in a one-by-one fashion using Dunn's post-hoc test. Ages of patients with hormone receptor-positive vs. -negative WDLS/DDLS were compared by $t$-test. Genders and races were compared for hormone receptor positivity using Fisher's exact test and Chi-square analysis, respectively. $p \leq 0.05$ was considered significant.

\section{Results}

\section{Frequent expression of ER and AR in WDLS and DDLS}

IHC staining of 561 specimens obtained from 379 LS tumors from 353 patients (characteristics listed in Table 1) revealed nuclear ER and AR expression in a significant number of cases (Figure 1). PR staining was less frequently observed. Using the stringent threshold of $10 \%$ positivelystained nuclei, we observed the following: $43.1 \%$ of WDLS, $17.5 \%$ of DDLS, $0 \%$ of PLS, and $5.2 \%$ of MLS were scored as ER+; $9.8 \%$ of WDLS, $7.6 \%$ of DDLS, $0 \%$ of PLS, and $5 \%$ of MLS were scored as PR+; $58.1 \%$ of WDLS, $24.1 \%$ of DDLS, $6.2 \%$ of PLS, and $9.1 \%$ of MLS were scored as AR + (Figure 2A). Using the threshold of $1 \%$ positively-stained nuclei used in the histological classification of breast cancer, we observed the following: $52.8 \%$ of WDLS, $22.5 \%$ of DDLS, $3.3 \%$ of PLS, and $10.4 \%$ of MLS were scored as ER+; $16.5 \%$ of WDLS, $10.2 \%$ of DDLS, $0 \%$ of PLS, and $9 \%$ of MLS were scored as PR+; 70\% of WDLS, $36.2 \%$ of DDLS, $15.6 \%$ of PLS, and $19.2 \%$ of MLS were scored as AR + .

Since a significant number of specimens expressed ER or AR, we compared IHC scores between histologic subtypes. We detected a statistically significantly higher frequency of ER and AR expression in WDLS compared to each other subtype (Figure $2 \mathrm{~B}$, all $p<0.001$ ). While some DDLS specimens expressed ER and AR, this subtype was not significantly different from PLS or MLS. PR was
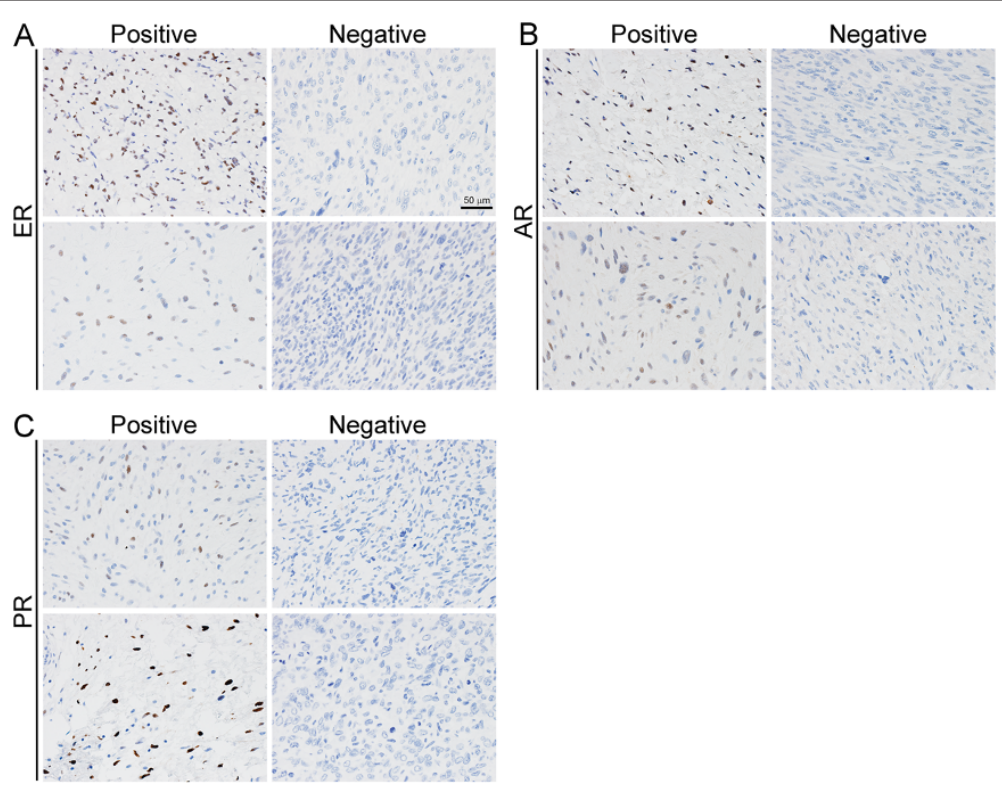

Figure 1 Steroid hormone receptor expression in LS. Sections of LS were stained using antibodies against A) ER, B) AR, or C) PR. Shown are two representative microscopic fields that were scored as receptor-positive or -negative. Scale bar in (A) is $50 \mu \mathrm{m}$. 


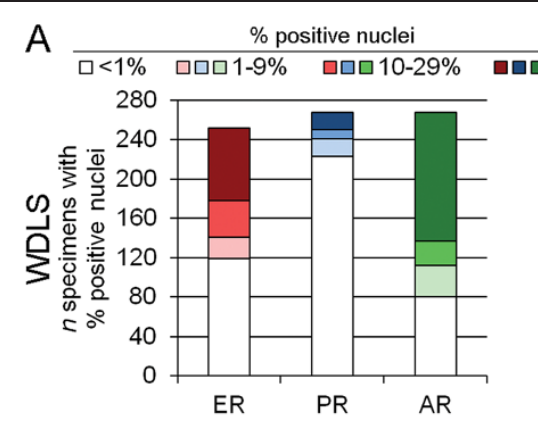

$30-100 \%$
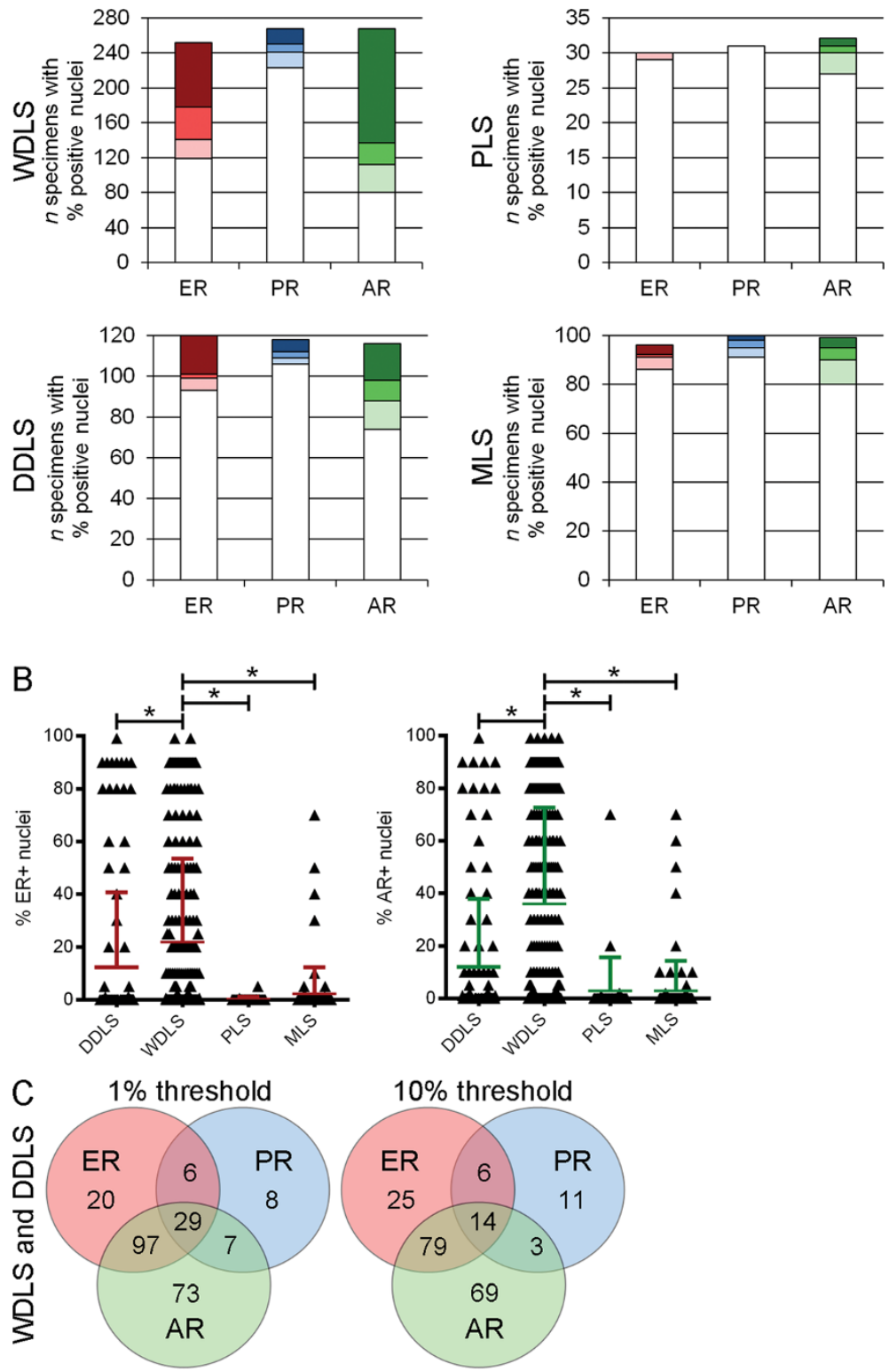

Figure 2 Steroid hormone receptor expression is most common in WDLS. A) LS specimens were scored for\% positively-stained nuclei for $E R, P R$, and AR, then classified by histological subtype and binned according to score as indicated. B) ER and AR scores were compared between specimen subtypes. Colored bars indicate mean + SD. ${ }^{*} p<0.0001$ by Dunn's post-hoc test. C) Venn diagrams illustrating the number of WDLS and DDLS specimens with co-expression of hormone receptors using a threshold of $1 \%$ or $10 \%$ positively-stained nuclei.

not significantly differentially expressed across histologic subtypes.

We then used Venn diagrams to determine the frequency of receptor co-expression within the combined WDLS and DDLS subtypes. Among 347 WDLS/DDLS specimens for which ER and AR IHC were evaluable, ER and AR were co-expressed in $28 \%$ and $22.8 \%$ of specimens at the $10 \%$ and $1 \%$ thresholds, respectively (Figure $2 \mathrm{C}$ ).
Intratumor heterogeneity in ER and AR expression

We observed that hormone receptor expression sometimes differed between tumors acquired from the same patient who underwent multiple surgeries over time. We therefore systematically evaluated hormone receptor expression levels over time in 53 patients who underwent $\geq 2$ surgeries to remove WDLS and/or DDLS (Figure 3). This analysis revealed that many tumors show changes in 


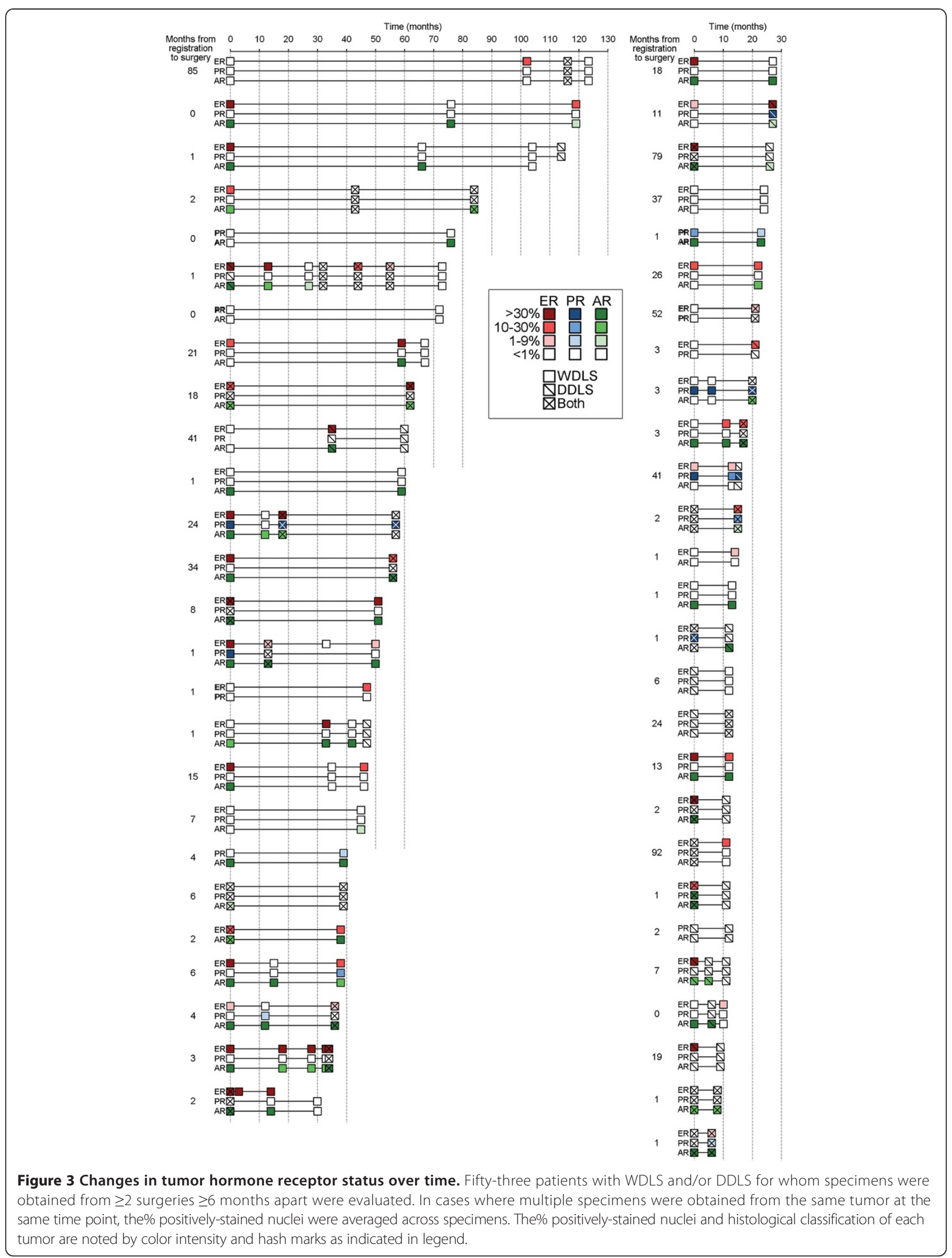




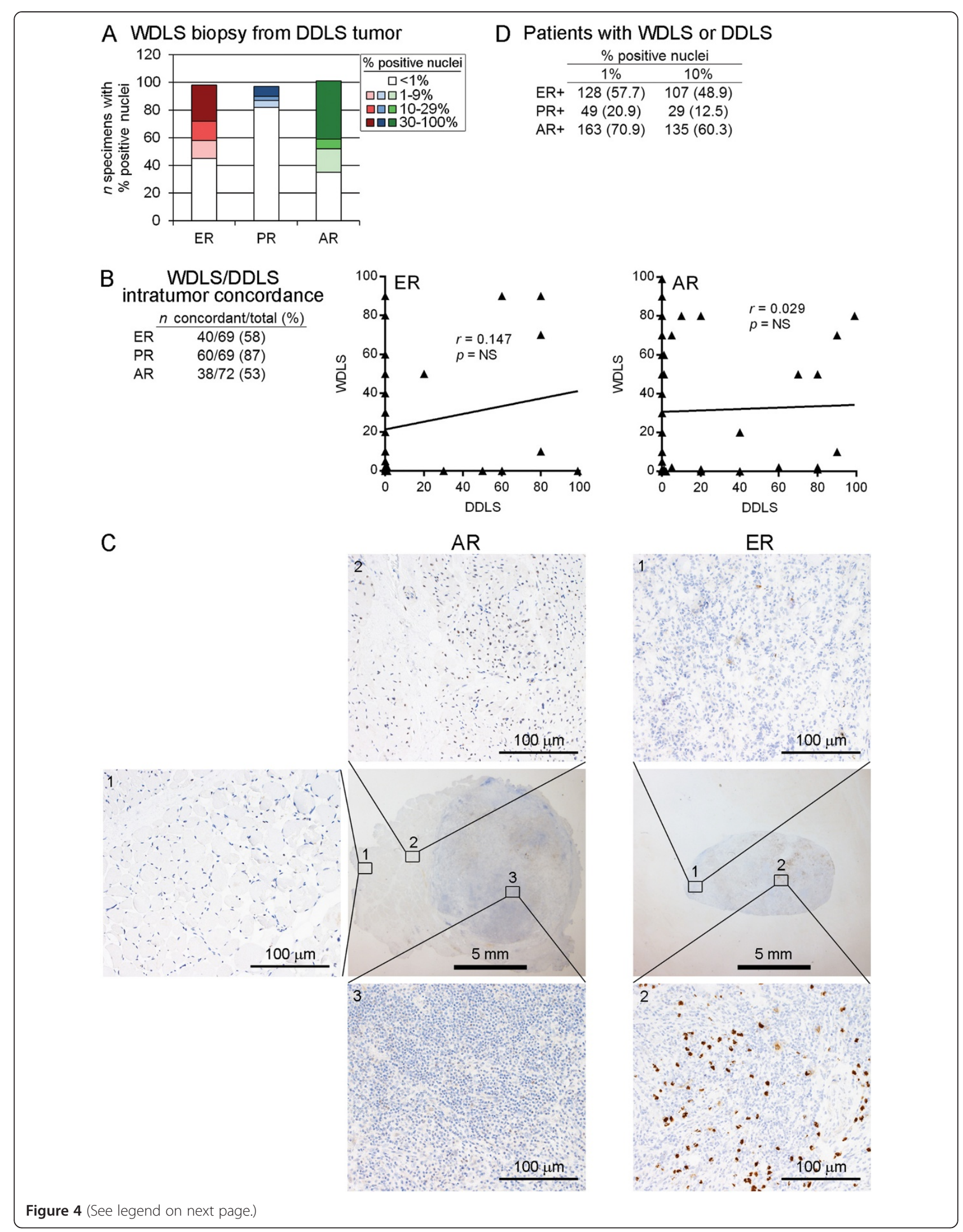


(See figure on previous page.)

Figure 4 Intratumor heterogeneity in degree of differentiation contributes to heterogeneity in hormone receptor expression. A) Frequencies of hormone receptor expression among WDLS specimens obtained from tumors classified as DDLS. B) Tumors for which 2 specimens were obtained from different regions at the same time point were evaluated for concordance in hormone receptor expression using a threshold of 10\% for positivity. Scatterplots show\% positive nuclei for ER and AR in tumors for which one DDLS specimen and one WDLS specimen were available. C) Representative liposarcoma specimens showing regions of receptor-positivity and -negativity. D) Hormone receptor status for patients with WDLS/DDLS as determined using any LS specimen obtained from any surgery.

hormone receptor expression over time, which may be attributable in part to intratumor heterogeneity, varying degrees of de-differentiation, and biopsy bias.

DDLS represents a form of tumor progression in WDLS, and both histologies may co-exist within the same tumor. We evaluated DDLS tumors with synchronous foci of WDLS and DDLS histologies for hormone receptor expression. At a threshold of $10 \%$ positively-stained nuclei, $40.8 \%, 10.3 \%$, and $48.5 \%$ of WDLS foci were ER+, PR+, and $\mathrm{AR}+$, respectively. At a $1 \%$ threshold, $54.1 \%, 15.5 \%$, and $65.3 \%$ of WDLS foci were ER+, PR+, and AR+, respectively (Figure 4A). Therefore, ER and AR expression are common in WDLS foci within otherwise DDLS tumors.

We then determined the rate of concordance for hormone receptor expression between 2 specimens obtained from different regions of the same WDLS/DDLS tumor; 75 tumors were available for this analysis. Using a threshold of $10 \%$ positively-stained nuclei, this analysis revealed rates of $58 \%$ and $53 \%$ concordance for ER and AR, respectively (Figure 4B). Ninety-two percent (69/75) of these tumors had specimens histologically classified as WDLS and DDLS (one of each). Among the ER-discordant tumors, $82.8 \%(24 / 29)$ showed an ER + WDLS specimen and an ER- DDLS specimen (Figure 4B). Among the ARdiscordant tumors, 73.7\% (28/38) showed an AR + WDLS specimen and an AR- DDLS specimen. These data suggest that the high degree of intratumor discordance in ER and AR expression (demonstrated with representative specimens in Figure 4C) is partially attributable to the degree of de-differentiation.

Given that tumor hormone receptor status changed over time (Figure 3), we evaluated associations between patient characteristics and hormone receptor expression using hormone receptor status (threshold of $10 \%$ positivelystained nuclei) determined from A) a specimen obtained from the first surgery performed at M.D. Anderson Cancer Center, or B) hormone receptor positivity from a specimen obtained from any WDLS/DDLS surgical specimen (i.e., patient had a receptor-positive specimen at any time point; frequencies shown in Figure 4D). The latter criterion indicated that $48.9 \%$ and $60.3 \%$ of patients had ER + or AR + WDLS/DDLS at some point during the course of their disease. Hormone receptor status was not significantly associated with gender, race, or tumor size. There was a significant association linking AR expression with earlier age at WDLS/DDLS diagnosis, and a trend linking PR expression with earlier age at diagnosis (Tables 2 and 3). However, the mean ages of onset were similar between receptor-positive and -negative groups. ER and AR expression were not associated with recurrence-free survival in patients with WDLS and/or DDLS using either criterion.

Table 2 Receptor positivity at any time point

\begin{tabular}{|c|c|c|c|c|c|c|c|}
\hline & & \multirow[b]{2}{*}{$n$} & \multirow[b]{2}{*}{ Age (years) } & \multirow[b]{2}{*}{ t-test $p$} & \multicolumn{2}{|c|}{ Gender } & \multirow[b]{2}{*}{ Fisher's $\mathrm{p}$} \\
\hline & & & & & Male & Female & \\
\hline \multirow[t]{4}{*}{$E R$} & Negative & 117 & $60.6 \pm 11.8$ & & 74 & 43 & \\
\hline & Positive & 102 & $59.6 \pm 11.1$ & NS & 57 & 45 & NS \\
\hline & Undetermined & 24 & & & 13 & 11 & \\
\hline & Total & 243 & & & 144 & 99 & \\
\hline \multirow[t]{4}{*}{$P R$} & Negative & 203 & $60.4 \pm 11.3$ & & 121 & 82 & \\
\hline & Positive & 28 & $56.4 \pm 13.2$ & 0.08 & 14 & 14 & NS \\
\hline & Undetermined & 12 & & & 9 & 3 & \\
\hline & Total & 243 & & & 144 & 99 & \\
\hline \multirow[t]{4}{*}{$A R$} & Negative & 90 & $61.3 \pm 11.8$ & & 52 & 38 & \\
\hline & Positive & 134 & $58.6 \pm 11.4$ & 0.09 & 83 & 51 & NS \\
\hline & Undetermined & 19 & & & 9 & 10 & \\
\hline & Total & 243 & & & 144 & 99 & \\
\hline
\end{tabular}


Table 3 Receptor positivity at time of first surgery

\begin{tabular}{|c|c|c|c|c|c|c|c|}
\hline & & \multirow[b]{2}{*}{$n$} & \multirow[b]{2}{*}{ Age (years) } & \multirow[b]{2}{*}{ t-test p } & \multicolumn{2}{|c|}{ Gender } & \multirow[b]{2}{*}{ Fisher's p } \\
\hline & & & & & Male & Female & \\
\hline \multirow[t]{4}{*}{$E R$} & Negative & 124 & $60.9 \pm 11.3$ & & 80 & 44 & \\
\hline & Positive & 90 & $59.1 \pm 11.6$ & NS & 50 & 40 & NS \\
\hline & Undetermined & 29 & & & 14 & 15 & \\
\hline & Total & 243 & & & 144 & 99 & \\
\hline \multirow[t]{4}{*}{$P R$} & Negative & 202 & $60.4 \pm 11.3$ & & 122 & 80 & \\
\hline & Positive & 23 & $55.5 \pm 13.7$ & 0.06 & 11 & 12 & NS \\
\hline & Undetermined & 18 & & & 11 & 7 & \\
\hline & Total & 243 & & & 144 & 99 & \\
\hline \multirow[t]{4}{*}{$A R$} & Negative & 100 & $61.6 \pm 11.6$ & & 58 & 42 & \\
\hline & Positive & 122 & $58.0 \pm 11.5$ & 0.02 & 76 & 46 & NS \\
\hline & Undetermined & 21 & & & 10 & 11 & \\
\hline & Total & 243 & & & 144 & 99 & \\
\hline
\end{tabular}

\section{Discussion}

Given that WDLS have a significantly higher frequency of ER-positivity and AR-positivity than DDLS, and that WDLS foci within DDLS tumors are often ER + and/or $\mathrm{AR}+$, hormone receptor expression is likely associated with a more differentiated LS phenotype. WDLS is often locally aggressive and non-metastasizing, is treated with surgical resection, and occurs repeatedly particularly in the retroperitoneum or mediastinum. WDLS causes morbidity through uncontrolled local effects on vital organs, or through de-differentiation and metastasis. Therefore, therapeutics to control WDLS and prevent de-differentiation may be clinically valuable.

If ER and AR are functionally important for WDLS/ DDLS cell proliferation or viability, as is observed in other cancer types such as breast and prostate, anti-hormone therapies may prevent LS progression. However, we caution that hormone receptor expression does not necessarily indicate receptor dependence. AR is expressed in $70-90 \%$ of breast cancers [18], but clinical testing of antiandrogen therapy in unselected patients with breast cancer met with little success [19]. AR may be functionally important in certain breast cancer subtypes [20,21], and clinical testing of anti-androgen therapy in patients with such subtypes is ongoing. Furthermore, ER + breast tumors frequently co-express PR. Since PR is encoded by an ER-regulated gene, PR co-expression is typically indicative of ER function. Surprisingly, most ER + LS specimens are $P R-$, raising the possibility that ER is non-functional. Alternatively, ER may regulate a different set of genes in LS cells, and/or PR levels may be modulated by another mechanism (such as phosphorylation by mitogenactivated protein kinase (MAPK), which promotes degradation [22]).
In vitro evidence to support hormone receptor dependence in LS models would help elucidate receptor function, but few WDLS cell lines exist, and it is arguable whether such cell lines accurately model the disease (s). Transgenic mice that overexpress IL22 in adipocytes develop WDLS when fed a high-fat diet [23]. If such murine LS tumors are hormone receptor-positive, this may present a useful model to elucidate receptor functionality in LS. There have been no proof-of-principle clinical trials to evaluate the effects of anti-hormone therapies in LS based on pre-treatment tumor hormone receptor status. Another option to explore the role(s) of hormone receptors in LS would be a pilot presurgical clinical study, where patients who have undergone a diagnostic tumor biopsy would be treated with antihormone therapy for 2-3 weeks prior to surgical tumor resection. The diagnostic (pre-treatment) biopsy tissue is then compared to the surgical (post-treatment) specimen to determine whether levels of hormone receptordriven or cell cycle-related genes and proteins have changed. This strategy may be useful to identify LS patients who will (or will not) benefit from adjuvant endocrine therapy [24].

\section{Conclusions}

In summary, we demonstrate that a significant fraction of WDLS and DDLS express ER and/or AR. The hormone receptor scoring method used herein is not finely calibrated, which may affect assay sensitivity; however, a less sensitive scoring method may be more likely to detect only cases with more robust (and, likely, more biological important) expression of these receptors. While there appears to be intratumor heterogeneity in hormone receptor expression, both between well- and de-differentiated areas 
of the same tumor, and over time within a patient's tumor (which may be partially attributable to biopsy bias), endocrine therapeutics may be useful to control hormone receptor-driven LS cells and mitigate disease progression.

\section{Abbreviations}

ER: Estrogen receptor alpha; PR: Progesterone receptor; AR: Androgen receptor; LS: Liposarcoma; WDLS: Well-differentiated liposarcoma; DDLS: De-differentiated liposarcoma; MLS: Myxoid liposarcoma; PLS: Pleomorphic liposarcoma.

\section{Competing interests}

The authors declare that they have no competing interests.

\section{Authors' contributions}

TWM and DCL designed the study. DR, DCL, AL, EGD, and TWM procured tissue samples, generated the tissue microarray, and performed $\mathrm{HC}$ staining. TWM, LD, and BLG scored IHC staining and analyzed data. TWM wrote the manuscript. All authors read, provided input on, and approved the final manuscript.

\section{Acknowledgements}

We thank the Norris Cotton Cancer Center Pathology Translational Research and Microscopy Shared Resources.

\section{Funding}

This work was supported by the National Institutes of Health R00CA142899 (T.W.M.). We thank the Lobo, Margolis, and Jackson families for their continued support of liposarcoma research.

\section{Author details}

${ }^{1}$ Departments of Surgical Oncology, M.D. Anderson Cancer Center, University of Texas, 1515 Holcombe Blvd, Houston, TX, USA. ²Departments of Pharmacology \& Toxicology, Norris Cotton Cancer Center, Geisel School of Medicine at Dartmouth, Dartmouth-Hitchcock Medical Center, One Medical Center Drive, HB-7936, Lebanon, NH 03756, USA. ${ }^{3}$ Departments of Surgical Pathology, M.D. Anderson Cancer Center, University of Texas, 1515 Holcombe Blvd, Houston, TX, USA. ${ }^{4}$ Departments of Surgery, Norris Cotton Cancer Center, Geisel School of Medicine at Dartmouth,

Dartmouth-Hitchcock Medical Center, One Medical Center Dr, Lebanon, NH, USA. ${ }^{5}$ Department of Pathology, Mount Sinai Medical Center, One Gustave L. Levy PI, New York, NY, USA.

Received: 8 July 2014 Accepted: 13 October 2014 Published: 22 October 2014

\section{References}

1. American_Cancer_Society: Breast Cancer Facts \& Figures 2011-2012. In Book Breast Cancer Facts \& Figures 2011-2012. Atlanta, GA: American Cancer Society, Inc.

2. Crago AM, Singer S: Clinical and molecular approaches to well differentiated and dedifferentiated liposarcoma. Curr Opin Oncol 2011, 23:373-378

3. Dalal KM, Kattan MW, Antonescu CR, Brennan MF, Singer S: Subtype specific prognostic nomogram for patients with primary liposarcoma of the retroperitoneum, extremity, or trunk. Ann Surg 2006, 244:381-391.

4. Henricks WH, Chu YC, Goldblum JR, Weiss SW: Dedifferentiated liposarcoma: a clinicopathological analysis of 155 cases with a proposal for an expanded definition of dedifferentiation. Am J Surg Pathol 1997, 21:271-281

5. McCormick D, Mentzel T, Beham A, Fletcher CD: Dedifferentiated liposarcoma. Clinicopathologic analysis of 32 cases suggesting a better prognostic subgroup among pleomorphic sarcomas. Am J Surg Pathol 1994, 18:1213-1223.

6. Hasegawa T, Seki K, Hasegawa F, Matsuno Y, Shimodo T, Hirose T, Sano T, Hirohashi S: Dedifferentiated liposarcoma of retroperitoneum and mesentery: varied growth patterns and histological grades-a clinicopathologic study of 32 cases. Hum Pathol 2000, 31:717-727.

7. Kallio A, Guo T, Lamminen E, Seppanen J, Kangas L, Vaananen HK, Harkonen P: Estrogen and the selective estrogen receptor modulator (SERM) protection against cell death in estrogen receptor alpha and beta expressing U2OS cells. Mol Cell Endocrinol 2008, 289:38-48.

8. Bulun SE, Chen D, Moy I, Brooks DC, Zhao H: Aromatase, breast cancer and obesity: a complex interaction. Trends Endocrinol Metab 2012, 23:83-89.

9. Shin JH, Hur JY, Seo HS, Jeong YA, Lee JK, Oh MJ, Kim T, Saw HS, Kim SH: The ratio of estrogen receptor alpha to estrogen receptor beta in adipose tissue is associated with leptin production and obesity. Steroids 2007, 72:592-599.

10. Chaudhuri PK, Walker MJ, Beattie CW, Das Gupta TK: Presence of steroid receptors in human soft tissue sarcomas of diverse histological origin Cancer Res 1980, 40:861-865.

11. Chaudhuri PK, Walker MJ, Beattie CW, Das Gupta TK: Distribution of steroid hormone receptors in human soft tissue sarcomas. Surgery 1981, 90:149-153.

12. Chaudhuri PK, Walker MJ, Beattie CW, Das Gupta TK: The steroid hormone receptors in tumors of adipose tissue. J Surg Oncol 1985, 28:87-89.

13. Weiss SW, Langloss JM, Shmookler BM, Malawer MM, D'Avis J, Enzinger FM, Stanton R: Estrogen receptor protein in bone and soft tissue tumors. Lab Invest 1986, 54:689-694.

14. Suda A, Sato T, Watanabe Y, Yamakawa M, Imai Y: Immunohistochemical study of steroid hormones and an estrogen binding assay in malignant soft tissue tumors. Nihon Seikeigeka Gakkai zasshi 1990, 64:814-823.

15. Li XQ, Hisaoka M, Hashimoto $H$ : Expression of estrogen receptors alpha and beta in soft tissue sarcomas: Immunohistochemical and molecular analysis. Pathol Int 2003, 53:671-679.

16. Valkov A, Sorbye S, Kilvaer TK, Donnem T, Smeland E, Bremnes RM, Busund LT: Estrogen receptor and progesterone receptor are prognostic factors in soft tissue sarcomas. Int J Oncol 2011, 38:1031-1040.

17. Sorbye SW, Kilvaer TK, Valkov A, Donnem T, Smeland E, Al-Shibli K, Bremnes RM, Busund LT: Prognostic impact of Skp2, ER and PGR in male and female patients with soft tissue sarcomas. BMC Clin Pathol 2013, 13:9.

18. Gonzalez LO, Corte MD, Vazquez J, Junquera S, Sanchez R, Alvarez AC, Rodriguez JC, Lamelas ML, Vizoso FJ: Androgen receptor expresion in breast cancer: relationship with clinicopathological characteristics of the tumors, prognosis, and expression of metalloproteases and their inhibitors. BMC Cancer 2008, 8:149.

19. Millward MJ, Cantwell BM, Dowsett M, Carmichael J, Harris AL: Phase II clinical and endocrine study of Anandron (RU-23908) in advanced post-menopausal breast cancer. Br J Cancer 1991, 63:763-764.

20. Lehmann BD, Bauer JA, Chen $X$, Sanders ME, Chakravarthy AB, Shyr $Y$, Pietenpol JA: Identification of human triple-negative breast cancer subtypes and preclinical models for selection of targeted therapies. J Clin Invest 2011, 121:2750-2767.

21. Ni M, Chen Y, Lim E, Wimberly H, Bailey ST, Imai Y, Rimm DL, Liu XS, Brown M: Targeting androgen receptor in estrogen receptor-negative breast cancer. Cancer Cell 2011, 20:119-131.

22. Lange CA, Shen T, Horwitz KB: Phosphorylation of human progesterone receptors at serine-294 by mitogen-activated protein kinase signals their degradation by the 26 S proteasome. Proc Natl Acad Sci U S A 2000, 97:1032-1037

23. Wang $Z$, Yang $L$, Jiang $Y$, Ling $Z Q$, Li Z, Cheng $Y$, Huang $H$, Wang $L$, Pan $Y$, Wang $Z$, Yan $X$, Chen $Y$ : High fat diet induces formation of spontaneous liposarcoma in mouse adipose tissue with overexpression of interleukin 22. PLoS One 2011, 6:e23737.

24. Dowsett M, Smith I, Robertson J, Robison L, Pinhel I, Johnson L, Salter J, Dunbier A, Anderson H, Ghazoui Z, Skene T, Evans A, A'Hern R, Iskender A, Wilcox M, Bliss J: Endocrine therapy, new biologicals, and new study designs for presurgical studies in breast cancer. J Natl Cancer Inst Monogr 2011, 2011:120-123.

doi:10.1186/1472-6890-14-42

Cite this article as: Ingram et al:: Estrogen receptor alpha and androgen receptor are commonly expressed in well-differentiated liposarcoma. BMC Clinical Pathology 2014 14:42. 